\title{
Implementation of Raman Lidar for Profiling of Atmospheric Water Vapor and Aerosols at the SGP CART Site
}

\author{
J. E. M. Goldsmith, Forest H. Blair, and Scott E. Bisson \\ Sandia National Laboratories \\ PO Box 969; MS 9057 \\ Livermore, CA 94551
}

There are clearly identified scientific requirements for continuous profiling of atmospheric water vapor at the SGP CART (southern great plains cloud and radiation testbed) site. Research conducted at several laboratories, including our work in a previous ARM Instrument Development Project, has demonstrated the suitability of Raman lidar for providing measurements that are an excellent match to those requirements. We are in the final stages of building a ruggedized Raman lidar system that will reside permanently at the CART site, and that is computer automated to reduce the requirements for operator interaction. In addition to the design goal of profiling water vapor through most of the troposphere during nighttime and through the boundary layer during daytime, the lidar will provide quantitative characterizations of aerosols and clouds, including depolarization measurements for particle phase studies.

Raman lidar systems detect selected species by monitoring the wavelength-shifted molecular return produced by Raman scattering from the chosen molecule or molecules, as illustrated in Fig. 1. For water-vapor measurements, the nitrogen Raman signal is observed simultaneously with the water-vapor Raman signal; proper ratioing of the signals yields the water-vapor mixing ratio. Similarly, by simultaneously recording the backscatter signal at the laser wavelength (which contains contributions from both Rayleigh and aerosol scattering), the ratio of the backscatter signal to the nitrogen Raman signal yields a quantitative measurement of the aerosol scattering ratio, and a variety of aerosol and cloud parameters can be derived from this measurement. In aerosol-free regions of the atmosphere, temperature profiles can be derived from the density measurements obtained from the nitrogen Raman signal. Finally, by adding polarizing optics and an additional direct-backscatter channel, depolarization measurements can provide information about the phase (water droplet or ice particle) of clouds detected by the lidar system.
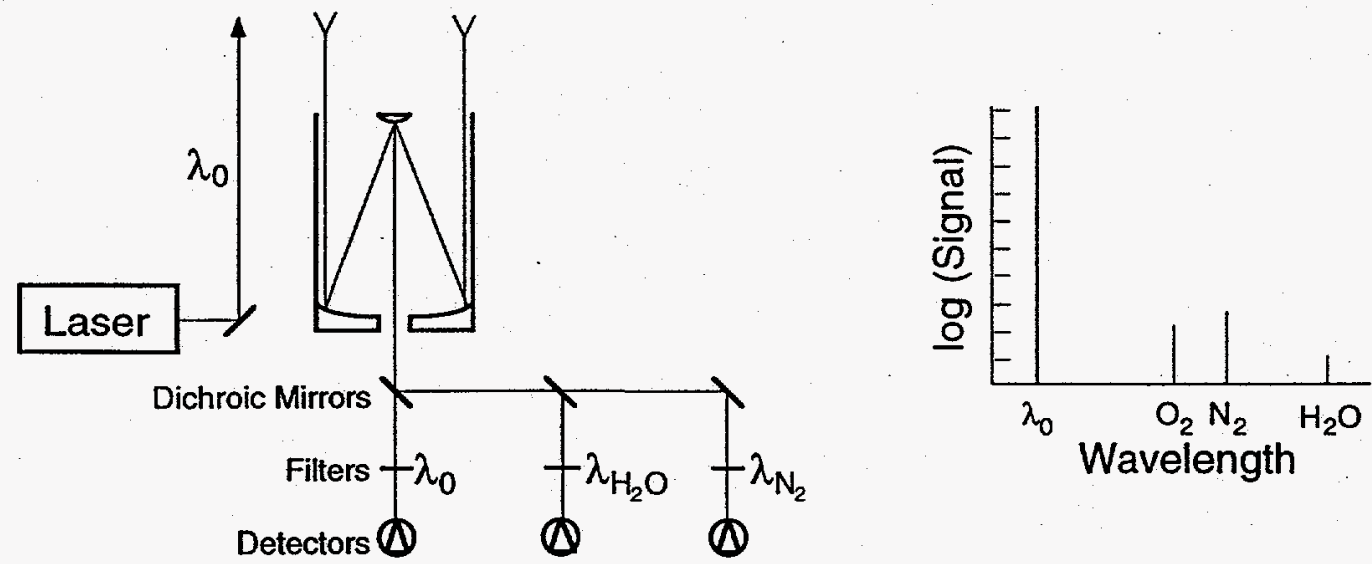

Fig. 1. Schematic diagram of idealized Raman lidar system, and signals produced by the primary species in the atmosphere.

\section{MASTER}




\section{DISCLAIMER}

This report was prepared as an account of work sponsored by an agency of the United States Government. Neither the United States Government nor any agency thereof, nor any of their employees, makes any warranty, express or implied, or assumes any legal liability or responsibility for the accuracy, completeness, or usefulness of any information, apparatus, product, or process disclosed, or represents that its use would not infringe privately owned rights. Reference herein to any specific commercial product, process, or service by trade name, trademark, manufacturer, or otherwise does not necessarily constitute or imply its endorsement, recommendation, or favoring by the United States Government or any agency thereof. The views and opinions of authors expressed herein do not necessarily state or reflect those of the United States Government or any agency thereof. 


\section{DISCLAIMER}

Portions of this document may be illegible in electronic image products. Images are produced from the best available original document. 
The Raman lidar system we are building to reside at the SGP CART site is housed in a seatainer, a metal shipping container that measures approximately $8^{\prime} \times 8^{\prime} \times 20^{\prime}$. The system is fully self-contained, requiring only an external supply of three-phase $208-V$ power. Optical access is provided by a weather-tight window in the roof of the seatainer; the window is covered by a motorized hatch during bad weather. A great deal of attention has been paid to the climatecontrol system to ensure reliable operation in the non-laboratory environment of the CART site. The overall layout of the system is shown in Fig. 2.

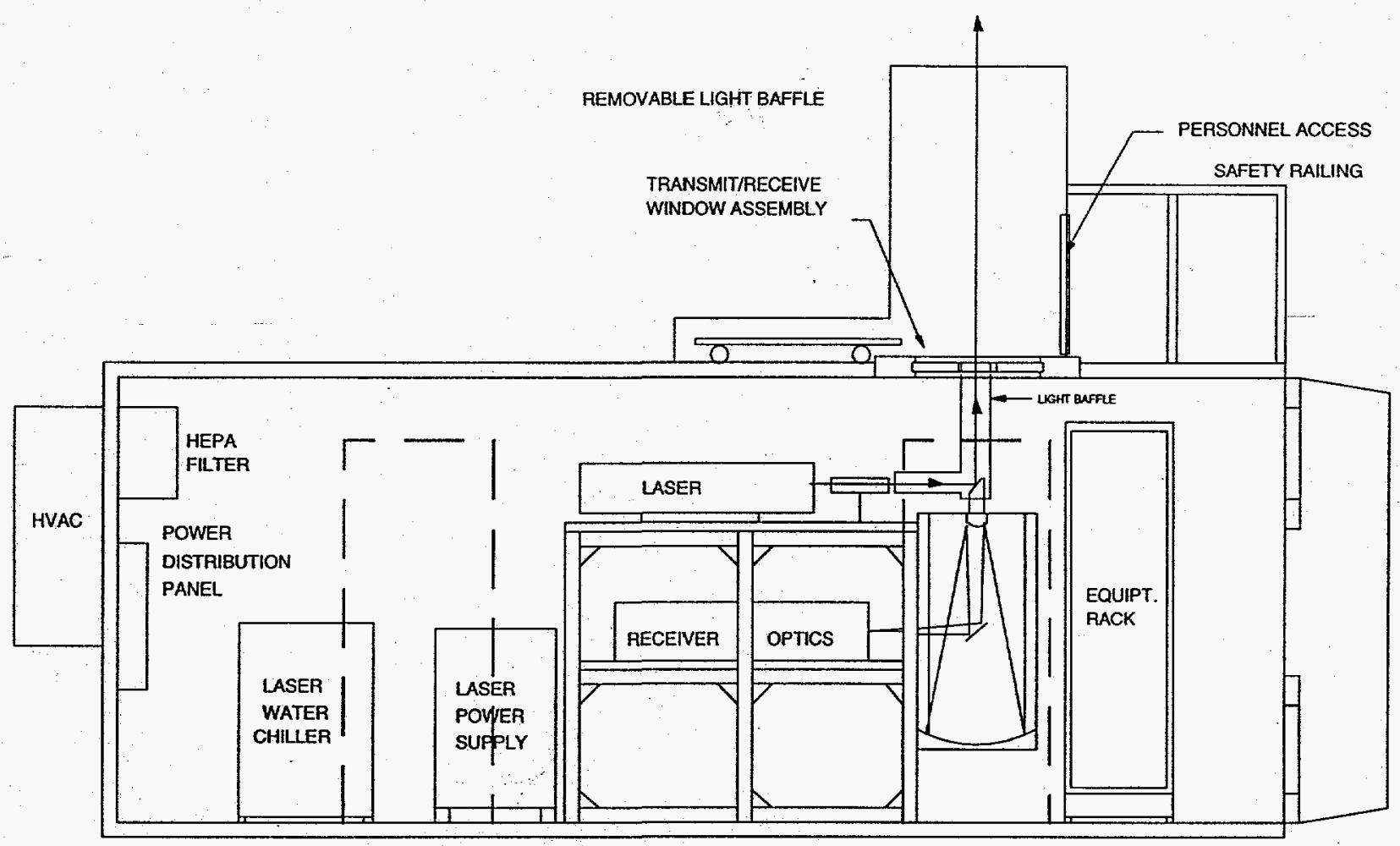

Fig. 2. Layout of the seatainer that houses the CART Raman lidar.

Two laser systems are good candidates for a Raman lidar system of this type, Nd:YAG lasers and excimer lasers; both have had considerable success in several systems. Although an excimer-based system has recently been developed at Sandia, we elected to use a frequencytripled Nd:YAG laser in the CART system. Nd:YAG lasers have four distinct advantages over excimer lasers: better beam quality (needed for narrow-field-of-view operation), more readily polarized (needed for depolarization measurements), no toxic gases required, and much lower cost for consumables and maintenance. Overall laser reliability is difficult to judge, although $\mathrm{Nd}$ :YAG lasers have the significant advantage of not requiring corrosive gases and having no moving parts. Excimer lasers do produce higher ultraviolet output power, but system performance modeling indicates that the higher power does not offset the other disadvantages.

The need to have a system that operates in both daytime and nighttime, and that can make accurate measurements both near the ground and at long ranges, places somewhat conflicting constraints on the system design. We have implemented a dual-field-of-view design to provide the best compromise among these requirements (see Fig. 3). The first beamsplitter in the path marked "from telescope" in Fig. 1 directs $5 \%$ of the light collected by the telescope through a relatively large aperture, which defines the "wide" field-of-view necessary to establish a 
transmitter-receiver overlap function which can record signals at short range. Dichroic beamsplitters direct the three wavelengths of interest through narrowband interference filters to photomultiplier tubes. This wide field-of-view produces a large solar background during the daytime, but this large background is offset by the large close-range signal. The remainder of the light collected by the telescope passes through a smaller aperture, which defines the "narrow" field of view, followed again by dichroic beamsplitters and narrowband interference filters, with an added polarizer and a second 355-nm channel for making depolarization measurements. The narrow field-of-view produces far less solar background, and provides optimum long-range signal. Our modeling indicates that this design will provide excellent daytime performance without sacrificing any nighttime capability.

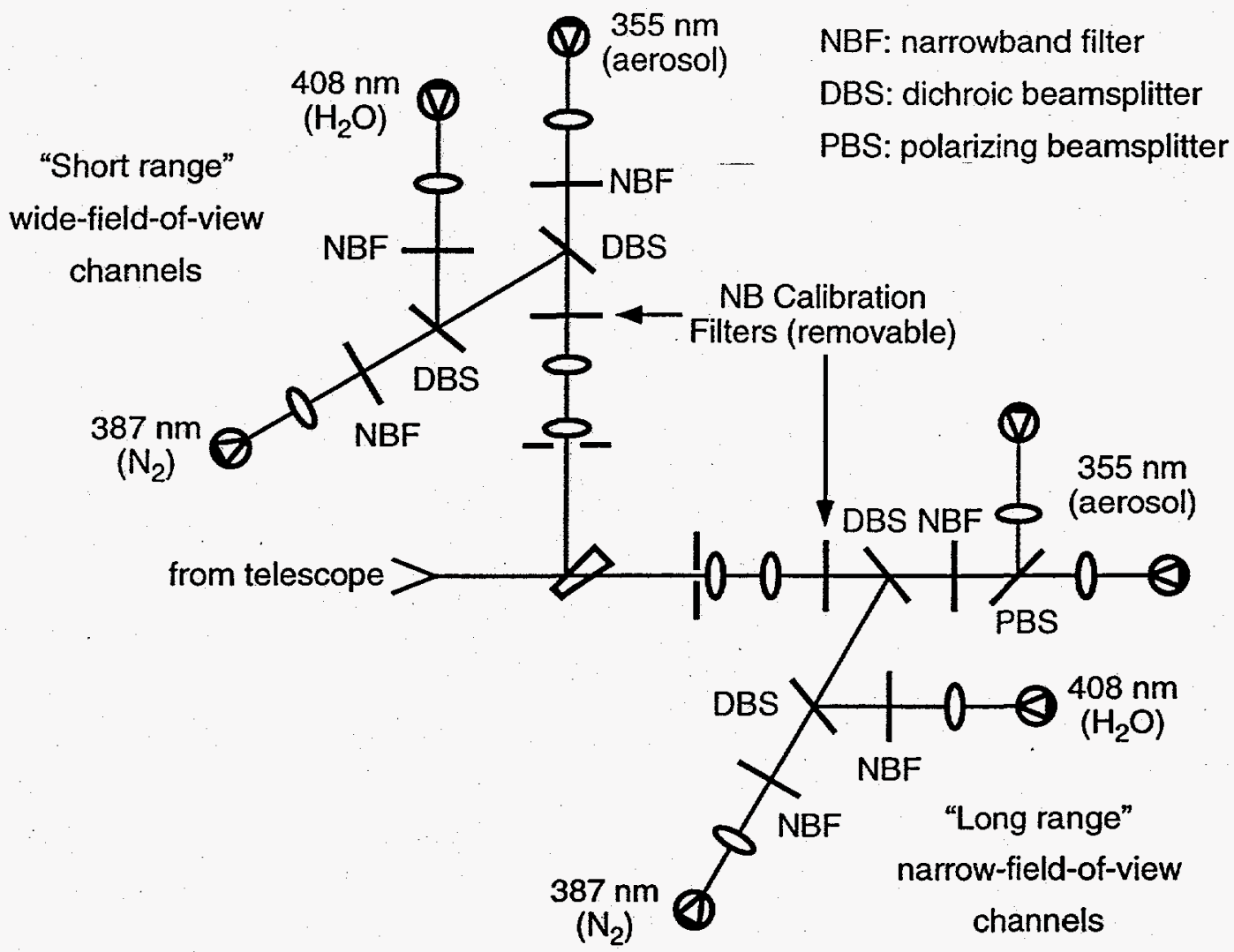

Fig. 3. Optical layout for dual-field-of-view Raman lidar receiver.

The lidar electronics have also been designed to optimize the performance of the dualfield-of-view design. Analog-to-digital conversion is being used for the short-range wide-fieldof-view channels, where large signals make photon counting very difficult, and photon counting is used for the narrow-field-of-view channels to provide optimum long-range performance. Detailed system specifications are listed in Table 1 below. To provide higher sensitivity for longer-range measurements that do not require such high resolution, the profiles can be averaged in time and/or space during post-processing. The system thus provides complete flexibility in trade-offs among sensitivity, spatial resolution, and temporal resolution, and these trade-offs can be explored at any time and with any range dependence desired. 
Table 1. System specifications

\begin{tabular}{|r|c|}
\hline \multicolumn{2}{|c|}{ Transmitter } \\
\hline Waser & Nd:YAG third harmonic \\
\hline Energy/pulse & $355 \mathrm{~nm}$ \\
\hline Repetition rate & $400 \mathrm{~mJ}$ \\
\hline Divergence & $30 \mathrm{~Hz}$ \\
\hline \hline \multicolumn{2}{|c|}{ Receiver } \\
\hline Configuration & Dall-Kirkham \\
\hline Diameter & $61 \mathrm{~cm}$ \\
\hline Channel bandpass & $\begin{array}{c}0.3 \mathrm{~nm} \text { (narrow fov) } \\
1.2 \mathrm{~nm} \text { (wide fov) }\end{array}$ \\
\hline Filter transmission & $30-40 \%$ \\
\hline Field of view & $\begin{array}{c}\text { Dual, adjustable } \\
\text { (typically 0.2 mr, 2 mr) }\end{array}$ \\
\hline Ranges & 2 (narrow, wide fov) \\
\hline Channels & 3 \\
\hline Species & $\begin{array}{c}\text { Rayleigh/aerosol (355 nm) } \\
\text { Water vapor (408 nm) } \\
\text { Nitrogen (387 nm) }\end{array}$ \\
\hline Averaging period & $15 \mathrm{~m}$ A/D \\
\hline Short range & Analog to Digital Conv. \\
\hline Electronics \\
\hline
\end{tabular}

The entire system is operated by a LabView-based program implemented on a conventional Windows-based PC. The program optimizes the doubling and tripling crystals in the laser, centers the laser beam in the receiver field-of-view, interchanges interference filters for a calibration procedure, acquires the data, processes it in real time, and produces real-time displays of the data. The measurements will be automatically transferred to the central CART computer system over ethernet, where they will be integrated into the automated data processing environment of the ARM data system.

The Raman lidar system described here provides an excellent match to the scientific requirements for continuous profiling of atmospheric water vapor at the SGP CART site. Because the system is under final construction even as this is being written, we cannot present any measurements at this time. However, our previous experience with Raman lidar indicates that this system can provide measurements of the quality desired. Much of the challenge in building the system comes from the desire to make the transition from a research-style system that is partially automated to a field-hardened, CART-ready system that has a greater degree of computer automation and requires significantly less operator attention. 